\title{
AVALIAÇÃO DA EVIDENCIAÇÃO DA REMUNERAÇÃO DOS ADMINISTRADORES E OS NÍVEIS DE GOVERNANÇA CORPORATIVA
}

\author{
Diego Rafael Stüpp ${ }^{1}$, Ilaci Pavesi ${ }^{1}$, Ernesto Fernando Rodrigues Vicente ${ }^{1}$, Luiz Alberton ${ }^{1}$ \\ ${ }^{1}$ Universidade Federal de Santa Catarina \\ diegostupp@brturbo.com.br, ilacip@terra.com.br, e.fernando@cse.ufsc.br, \\ luiz.alberton@ufsc.br
}

\begin{abstract}
Resumo
A governança corporativa surgiu como proposta de minimização dos conflitos e custos decorrentes do problema de agência. E este estudo tem por objetivo verificar como se encontra a evidenciação da remuneração dos administradores nas empresas brasileiras listadas na BM\&FBOVESPA com maior e menor nível de governança corporativa, com base no do modelo europeu de avaliação proposto por Ferrarini, Maloney e Ungureanu (2009). Trata-se de um estudo descritivo quanto aos objetivos, no que se refere aos procedimentos técnicos enquadra-se como pesquisa documental na base de dados obtida a partir do Formulário de Referencia das companhias listadas na BM\&FBOVESPA. Quanto à abordagem do problema apresenta-se como um estudo quantitativo com a aplicação do teste de hipóteses denominado teste $t$ de Student. Têm-se como amostra da pesquisa 20 empresas sendo 10 do segmento de governança corporativa do Novo Mercado e outras 10 do Tradicional. Os resultados do trabalho mostram maior grau de evidenciação nas empresas do Novo Mercado para as áreas de governança e evidenciação individual dos executivos e não executivos, enquanto para a área de política de evidenciação, o nível encontra-se semelhante.
\end{abstract}

Palavras-chave: Governança Corporativa. Remuneração de Administradores. Evidenciação.

\begin{abstract}
Corporate governance has emerged as proposed minimization of conflicts and costs of agency problem. This essay has the objective to verify what is the status of the disclosure about administrators remuneration in Brazilian companies listed in BM\&FBOVESPA with bigger and smaller level of corporate governance, based on the European evaluation model indicated by Ferrarini, Maloney and Ungureanu (2009). This essay is a descriptive study as for the objectives; as for the technical procedures, it is considered as documental research based on data obtained from the Reference Form of the BM\&FBOVESPA listed companies. As for the approach of the problem, it is presented as a quantitative study with hypothesis test application test $t$ of Student. The sample of the research is of 20 companies, 10 from the New Market corporative governance segment and the other 10 from the Traditional segment. The results of the essay show a higher level of disclosure in companies from the New Market for governance, and individual examples of executives and non-executives, whereas for the political area, the disclosure is found in similar level.
\end{abstract}

Keywords: Corporate Governance. Managers Remuneration. Disclosure.

\section{Introdução}

R. Eletr. do Alto Vale do Itajaí - REAVI, v. 4, n. 5, p. I- F, mar., 2016.

ISSN 2316-4190, DOI: 10.5965/2316419004052015001 


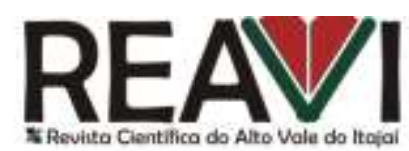

Universidade do Estado de Santa Catarina

Centro de Educação Superior do Alto Vale do Itajaí

O Instituto Brasileiro de Governança Corporativa - IBGC (2009) conceitua governança corporativa como sistema pelo qual as organizações são dirigidas, monitoradas e incentivadas, envolvendo os relacionamentos entre proprietários, conselho de administração, diretoria e órgãos de controle. A governança corporativa surgiu como proposta de minimização dos conflitos e custos decorrentes do problema de agência. Reforça Carvalho (2002) ao afirmar que governança corporativa é um conjunto de regras que visa minimizar os problemas de agência.

Neste sentido, Vieira e Mendes (2005) apregoam que a prática da boa governança nas empresas aparece como um recurso capaz de proporcionar maior transparência a todos os agentes envolvidos com a instituição, minimizando a assimetria de informação existente entre administradores e proprietários.

Yamamoto e Almeida Prado (2003), afirmam que a gestão inadequada de uma companhia, além de poder causar prejuízos internos aos seus acionistas, pode colocar em risco a credibilidade da empresa no mercado como um todo. No Brasil, a principal mudança no tratamento da remuneração dos administradores ocorreu com o advento da Instrução 480 da Comissão de Valores Mobiliários - CVM que passou a exigir a partir de 2010 a divulgação da remuneração dos administradores no Anexo 24 do Formulário de Referência.

As questões relacionadas à remuneração de administradores nas empresas é tema que desperta o interesse de pesquisadores no Brasil e no mundo. A pesquisa de Beuren e Silva (2012) verificou o alinhamento da evidenciação da remuneração dos executivos nas maiores empresas brasileiras listadas na BM\&F. A Bolsa de Valores, Mercadorias e Futuros com o modelo de avaliação da evidenciação desenvolvido por Ferrarini, Moloney e Ungureanu (2009). Os resultados evidenciaram que foram baixos os níveis de evidenciação das informações dos critérios de análise com o modelo aplicado na pesquisa.

Ventura (2013) estudou a relação entre a remuneração executiva, governança corporativa e desempenho nas empresas listadas pela BM\&FBOVESPA no período de 2009 a 2011. Quanto à análise da remuneração em relação aos níveis diferenciados de Governança Corporativa não houve uma grande divergência de resultados, concluindo que o pagamento da remuneração executiva independe do nível de Governança Corporativa a que a empresa esta inserida. A análise limitou-se à remuneração média paga à Diretoria estatutária.

Ferrarini, Moloney e Ungureanu (2009) examinaram o grau de governança da remuneração e práticas de divulgação nas 300 maiores empresas listadas da Europa com referência ao ano de 2007. A pesquisa sobre o grau de conformidade das empresas europeias com as recomendações da Comunidade Europeia e com as melhores práticas internacionais revelou que a divulgação da remuneração de administradores, varia de país para país.

$\mathrm{Na}$ busca por boas práticas de Governanca Corporativa, as empresas começarama aderir aos segmentos de listagem destinados a negociação de ações de empresas comprometendo-se, voluntariamente, com um nível de transparência adicional em relação ao que exige a legislação. Os denominados Níveis Diferenciados de Governanca Corporativa foram instituídos no final do ano de 2000 pela BM\&FBOVESPA - Bolsa de Valores, Mercadorias e Futuros de São Paulo, com a finalidade de dar mais proteção ao investidor atraves de controles eficientes, confiáveis e transparentes, proporcionando, assim, um diferencial competitivo no mercado para as empresas (VENTURA, 2013).

Deduz-se assim que quanto maior o nível de governança, maior seria a transparência das informações prestadas pela empresa aos seus stakeholders. Neste sentido o IBGC (2009) enfatiza que, das companhias listadas nos segmentos mais altos de governança, espera-se maior comprometimento com transparência.

Diante deste contexto, esta pesquisa pretende responder a seguinte questão: como se encontra a avaliação da evidenciação da remuneração dos administradores nas empresas brasileiras listadas na BM\&FBOVESPA nos diversos níveis diferenciados de governança corporativa? 


\section{REAVI}

Universidade do Estado de Santa Catarina

Centro de Educação Superior do Alto Vale do Itajaí

Neste sentido, a pesquisa utilizou as informações constantes no Formulário de Referência publicado na BM\&FBOVESPA. Justifica-se o estudo pela relevância da informação contábil para os stakeholders e pelo tema ser atual dada a obrigatoriedade emanada pela CVM, exigindo um maior grau de transparênciapelas empresas de capital aberto no que tange à divulgação de dados referentes às remunerações dos administradores. A utilização do modelo de avaliação da evidenciação de informações desenvolvido por Ferrarini, Maloney e Ungureanu (2009) é justificada por ter sido baseada na regulamentação aplicável à determinação da remuneração dos executivos na Europa, um mercado mais desenvolvido e evoluído na questão do disclosure.

Em termos de organização, divide-se este trabalho em seis seções. Após esta de caráter introdutório apresenta-se a revisão da literatura a respeito da Teoria da Agência, Evidenciação da Remuneração dos Executivos e o Modelo de avaliação da evidenciação de Remuneração de Ferrarini, Maloney e Ungureanu (2009). Como terceira seção apresenta-se a metodologia utilizada para responder o problema de pesquisa. Na sequência apresentam-se os resultados obtidos com as análises. Posteriormente, como quinta seção se apresentam as conclusões obtidas neste estudo. Por fim, se apresentam as referências utilizadas como base de sustentação teórica do desenvolvimento deste estudo.

\section{Referencial Teórico}

O referencial teórico deste trabalho está dividido em três tópicos principais, onde inicialmente é conceituada a teoria da agência, que deu suporte teórico para o estudo das práticas de evidenciação da remuneração dos executivos. O segundo tópico tratou das normas brasileiras de evidenciação de remuneração dos administradores. E por fim foi apresentado o modelo desenvolvido por Ferrarini, Maloney e Ungureanu (2009).

\subsection{Teoria da Agência}

Jensen e Meckling (1976) definem o relacionamento de agência como um contrato no qual uma ou mais pessoas (principal) contratam outra pessoa (agente) para realizar alguma atividade em seu nome ou a seu mando, delegando autoridade ao agente. Os autores partem do pressuposto que nenhum indivíduo pode desejar maximizar uma função que não seja a sua, devido ao seu comportamento que está fundamentado no conjunto de suas preferências e em seus objetivos.

Godoy e Marcon (2008) fundamentam que a Teoria da Agência tem sido de grande valia no entendimento das diversas relações entre principal e agente, em diversos setores no ambiente organizacional, e busca estabelecer e identificar os incentivos que levam o agente executar o que dele se espera, de forma a atender aos interesses do principal.

Conforme Hendriksen e Van Breda (2007), sob a ótica da Teoria da Agência, o agente tem o compromisso de realizar algumas atividades para o principal, assim, o principal tem o compromisso de remunerar o agente pela execução da atividade.

$\mathrm{Na}$ tentativa de encontrar uma solução otimizada para eliminar, ou pelo menos reduzir uma eventual distância existente entre o que o principal espera e o que efetivamente é realizado pelo agente, ocorrem alguns custos, chamados de custos de agência. Jensen e Meckling (1976) classificam tais custos em custos de controle (monitoringcosts), custos de obrigação (bondingcosts) e custos residuais (residual loss):

a) Custos de controle ou de vigilância - são as despesas suportadas pelo principal com o objetivo de verificar e acompanhar se o agente atua para defender os seus interesses.

b) Custos de obrigação ou de justificação - são os encargos que o principal assume perante o agente para justificar que suas decisões foram do interesse desses. 


\section{REAVI}

Universidade do Estado de Santa Catarina

Centro de Educação Superior do Alto Vale do Itajaí

c) Custos residuais - derivam dos dois tipos anteriores e correspondem à noção de custos de oportunidade. Esse tipo de custo decorre do fato de o principal não exagerar no controle, ou seja, o custo do controle não pode ser superior ao ganho gerado pelo controle; desse modo, pode ocorrer certo abandono do controle, dando origem aos custos residuais.

\subsection{Evidenciação da Remuneração de Administradores}

Os problemas de agência e o papel da governança corporativa têm demandado atenção dos órgãos orientadores e normatizadores sobre a evidenciação da remuneração dos executivos. No Brasil, a necessidade de maior transparência na evidenciação de informações relativas à remuneração dos principais gestores das organizações, implicou que o principal órgão relativo à condução das melhores práticas de governança corporativa, o Instituto Brasileiro de Governança Corporativa (IBGC), e o principal regulador do mercado de capitais, a Comissão de Valores Mobiliários (CVM), publicassem e regulamentassem novas práticas de evidenciação da remuneração variável dos executivos (SILVA E BEUREN, 2009).

A Instrução CVM n ${ }^{\circ}$ 480/09 traz uma lista de informações a serem divulgadas sobre remuneração de administradores na sessão 13 do anexo 24 (Formulário de Referência), é obrigatório para as empresas de capital aberto e deve ser elaborado anualmente.

Dentre as principais informações exigidas estão: a descrição da política e prática de remuneração dos conselhos e diretoria estatutária, os valores das remunerações, informações sobre remuneração baseada em ações e opções, planos de previdência, arranjos contratuais, apólices de seguros ou outros instrumentos que estruturam mecanismos de remuneração ou indenização para os administradores em caso de destituição do cargo ou de aposentadoria, dentre outros.

Considerando a necessidade de maior transparência na evidenciação de informações relativas à remuneração dos principais dirigentes das organizações, o Instituto Brasileiro de Governança Corporativa reformulou em 2009 o Código das Melhores Práticas de Governança Corporativa e alterou significativamente o item que trata a remuneração dos executivos (IBGC, 2009).

\subsection{Modelo de avaliação da evidenciação de remuneração de FERRARINI, MALONEY E UNGUREANU}

$\mathrm{Na}$ Europa, com o intuito de tornar as políticas e práticas de remuneração dos executivos mais transparente, foram criadas as Recomendações CE N. 913/2004, CE N. 162/2005 e mais recentemente a Recomendação CE N. 3177/2009. Baseando-se nessas recomendações, os pesquisadores Guido Ferrarini, Niamh Maloney e Maria Cristina Ungureanu, membros do ECGI - European Corporation Governance Institute, em seu trabalho "Understanding Directors' Pay in Europe: A Comparative and Empirical Analysis", desenvolveram um modelo para a avaliação da remuneração dos administradores. Ao aplicar o modelo em 300 empresas de dezessete estados-membro da União Europeia, através de questionários e formulário anual, o estudo conclui que apesar das reformas nos últimos anos e os esforços de harmonização, os níveis de divulgação ainda podem variar de país para país e são dependentes da existência de regulamentos (FERRARINI; MALONEY; UNGUREANU, 2009).

O modelo proposto está dividido em três áreas: Governança, Política de Remuneração e Evidenciação Individual dos Executivos e Não executivos. Além de oito categorias e vinte e três critérios, como demonstra o Quadro 1.

$\mathrm{Na}$ área de Governança é analisada a categoria 1- Comitê de Remuneração, com os critérios de existência e composição do Comitê de Remuneração, ou seja, a existência de um comitê de 


\section{REAVI}

Universidade do Estado de Santa Catarina

Centro de Educação Superior do Alto Vale do Itajaí

remuneração criada no âmbito do conselho (fiscal), ou separado ou unido com comitê de nomeação ou conforme o caso, que tem como (entre) as suas principais atribuições, o processo para estabelecer a remuneração dos administradores.

Na área de Política de Remuneração e Evidenciação dos Executivos, são analisadas quatro categorias cada qual com seus critérios. A categoria "Declaração de Política de Remuneração", cujos critérios abordados são a existência de tal declaração, a visão geral da política e o foco no futuro. $\mathrm{Na}$ categoria "Condições dos Contratos dos administradores executivos diretores" são analisados os critérios de duração dos contratos, aviso prévio e indenizações no caso de cessação dos contratos.

A categoria "Preparação e processo de tomada de decisão" é composta pelos critérios: mandato e composição, a divulgação dos nomes dos consultores externos cujos serviços foram utilizados na determinação da política de remuneração e o papel da assembléia geral no processo de fixação da remuneração.

A última categoria desta área, "Informações contidas na declaração de remuneração", mostra os critérios referentes à importância relativa entre remuneração fixa e variável, os principais parâmetros para o pagamento do bônus anual, os critérios de desempenho da remuneração baseada em ações e a articulação entre remuneração e desempenho.

$\mathrm{Na}$ terceira área do modelo os autores tratam da Remuneração Individual, que é analisada através de três categorias: "Remuneração Individual" que trata da divulgação individual dos executivos e dos não executivos; a categoria "Emolumentos" avalia os critérios de Salário/taxas, Bônus e demais benefícios e a Remuneração do ano anterior; a última categoria analisa os "Sistemas de incentivos com base em ações" através dos critérios de Ações/opções concedidas, exercidas e não exercidas.

O Quadro 1 representa a estrutura do modelo desenvolvido e proposto por Ferrarini, Maloney e Ungureanu (2009) para avaliação da evidenciação da remuneração dos administradores, modelo que se adotou neste estudo. 


\begin{tabular}{|c|c|}
\hline \multicolumn{2}{|c|}{ Area 1: GOVERNANÇA } \\
\hline \multicolumn{2}{|c|}{ Categoria1: Comitê de Remuneração } \\
\hline & Critério 1: Comitê de Remuneração: existente \\
\hline & Critério 2: Comitê de Remuneração: composição \\
\hline \multicolumn{2}{|c|}{ Area 2: POLÍTICA DE REMUNERAÇÃ O } \\
\hline \multicolumn{2}{|c|}{ Categoria 2: Declaração de Política de Remuneração } \\
\hline & Critério 3: Declaração: existente \\
\hline & Critério 4: Visão geral da política \\
\hline & Critério 5: perspectivas: foco no futuro \\
\hline \multicolumn{2}{|r|}{ Categoria 3: Termos do Contrato } \\
\hline & Critério 6: Duração do contrato \\
\hline & Critério 7: Período do aviso prévio \\
\hline & Critério 8: Indenizações \\
\hline \multicolumn{2}{|r|}{ Categoria 4: Preparação e processo de tomada de decisão } \\
\hline & Critério 9: Mandato e composição \\
\hline & Critério 10: Consultores externos \\
\hline & Critério 11: Papel da Assembléia Geral \\
\hline \multicolumn{2}{|c|}{ Categoria 5: Informações da Política } \\
\hline & Critério 12: Importância relativa fixo/variável \\
\hline & Critério 13: Principais parâmetros para o bônus anual \\
\hline & Critério 14: Critérios de desempenho para remuneração baseada em ações \\
\hline & Critério 15: Informações suficientes para relacionar remuneração $X$ desempenho \\
\hline \multicolumn{2}{|r|}{ Area 3: EVIDENCIAÇÃO INDIVIDUAL DOS EXECUTIVOS E NÃO-EXECUTIVOS } \\
\hline \multicolumn{2}{|r|}{ Categoria 6: Evidenciação individual } \\
\hline & Critério 16: Evidenciação individual dos executivos \\
\hline & Critério 17: Evidenviação individual dos não-executivos \\
\hline \multicolumn{2}{|r|}{ Categoria 7: Emolumentos } \\
\hline & Critério 18: Salário Individual / taxas \\
\hline & Critério 19: Bônus individual e outros benefícios \\
\hline & Critério 20: Informações do ano anterior \\
\hline \multicolumn{2}{|r|}{ Categoria 8: Sistemas de incentivo bas eado em ações } \\
\hline & Critério 21: Ações /opções concedidas \\
\hline & Critério 22: Ações / opções exercidas \\
\hline & Critério 23: Ações / opções não exercidas \\
\hline
\end{tabular}

Quadro 1 - Estrutura do modelo de avaliação da evidenciação da remuneração de administradores (Ferrarini, Maloney e Ungureanu, 2009).

\section{Metodologia da Pesquisa}

Quanto aos objetivos, a pesquisa considera-se descritiva. A pesquisa descritiva tem como objetivo principal a descrição das características de determinada população ou de determinado fenômeno, ou ainda o estabelecimento de relação entre as variáveis (GIL, 1991). Uma de suas peculiaridades está na utilização de técnicas padronizadas de coleta de dados (GIL, 2008).

No que se refere aos procedimentos técnicos trata-se de pesquisa documental que segundo Gil (2008), é muito parecido com a bibliográfica, cuja diferença está na natureza das fontes, pois esta forma vale-se de materiais que não receberam ainda um tratamento analítico, ou que ainda podem ser reelaborados de acordo com os objetos da pesquisa. A pesquisa utilizou-se de dados obtidos a partir do Anexo 24 do Formulário de Referencia publicado pelas companhias listadas no site da BM\&FBOVESPA. 
Quanto à forma de abordagem do problema apresenta-se como um estudo quantitativo. A abordagem quantitativa consiste no "emprego de quantificação tanto nas modalidades de informações, quanto no tratamento delas por meio de técnicas estatísticas" (RICHARDSON: 1989, p. 70). Nesta pesquisa utilizou-se o teste de hipóteses denominado teste $t$ de Student, que é um teste paramétrico que serve para comparar duas médias.

\subsection{Amostra}

Separou-se as empresas listadas na BM\&FBOVESPA por nível de governança corporativa (Tradicional, Nível 1, Nível 2 e Novo Mercado) e por Receita Operacional Líquida no ano de 2012, através do programa Economatica. Foram selecionadas as 10 empresas com maior Receita Operacional Líquida em cada um dos segmentos extremos de governança, ou seja, Tradicional e Novo Mercado.

Relaciona-se nas Tabelas 1 e 2, as empresas selecionadas para este estudo com suas respectivas Receitas Operacionais Líquidas em milhares de Reais, o percentual de participação da ROL - Receita Operacional Líquida no total das empresas em seus respectivos segmentos de nível de governança.

\begin{tabular}{c|l|l|r|c}
\hline $\mathbf{N}^{\mathbf{0}}$ & Empresa & Segmento & ROL Total em 2012 (\$) & Participação no Setor \\
\hline 1 & JBS & Novo Mercado & $75.696 .710,00$ & $16,25 \%$ \\
\hline 2 & ULTRAPAR & Novo Mercado & $53.919 .424,00$ & $11,58 \%$ \\
\hline 3 & BRF & Novo Mercado & $28.517 .383,00$ & $6,12 \%$ \\
\hline 4 & MARFRIG & Novo Mercado & $23.726 .394,00$ & $5,09 \%$ \\
\hline 5 & COSAN & Novo Mercado & $21.554 .967,00$ & $4,63 \%$ \\
\hline 6 & TIM & Novo Mercado & $18.763 .947,00$ & $4,03 \%$ \\
\hline 7 & EMBRAER & Novo Mercado & $12.201 .715,00$ & $2,62 \%$ \\
\hline 8 & SABESP & Novo Mercado & $10.754 .435,00$ & $2,31 \%$ \\
\hline 9 & MAGAZINE LUIZA & Novo Mercado & $7.665 .112,00$ & $1,65 \%$ \\
\hline 10 & ENERGIAS BR & Novo Mercado & $6.567 .283,00$ & $1,41 \%$ \\
\hline & Total & & $259.367 .370,00$ & $55,68 \%$ \\
\hline
\end{tabular}

Tabela 1 - Amostra das empresas do Segmento Novo Mercado

\begin{tabular}{c|l|l|r|c}
\hline $\mathbf{N}^{\mathbf{0}}$ & Empresa & Segmento & ROL Total em 2012 (\$) & Participação no Setor \\
\hline 1 & PETROBRAS & Tradicional & $281.379 .482,00$ & $44,17 \%$ \\
\hline 2 & ELETROBRAS & Tradicional & $39.538 .861,00$ & $6,21 \%$ \\
\hline 3 & TELEFÔNICA BRASIL & Tradicional & $33.931 .422,00$ & $5,33 \%$ \\
\hline 4 & AMBEV & Tradicional & $32.231 .027,00$ & $5,06 \%$ \\
\hline 5 & VIAVAREJO & Tradicional & $22.846 .250,00$ & $3,59 \%$ \\
\hline 6 & EMBRATEL & Tradicional & $18.781 .235,00$ & $2,95 \%$ \\
\hline 7 & CEMIG & Tradicional & $18.460 .375,00$ & $2,90 \%$ \\
\hline & SIDERURGICA & & & \\
\hline 8 & NACIONAL & Tradicional & $16.896 .264,00$ & $2,65 \%$ \\
\hline 9 & CPFL ENERGIA & Tradicional & $15.055 .147,00$ & $2,36 \%$ \\
\hline 10 & LOJAS AMERICANAS & Tradicional & $11.334 .061,00$ & $1,78 \%$ \\
\hline & Total & & $490.454 .124,00$ & $77,00 \%$ \\
\hline
\end{tabular}

Tabela 2 - Amostra das empresas do Segmento Tradicional 


\section{REAVI}

Universidade do Estado de Santa Catarina

Centro de Educação Superior do Alto Vale do Itajaí

Observa-se que na seleção da amostra, as dez empresas selecionadas do Novo Mercado representam 55,68\% do total de toda a Receita Operacional Líquida das empresas que compõe este nível de governança; as 10 empresas do selecionadas do nível de governança denominado Tradicional, representam $77 \%$ da ROL das empresas do seu segmento, totalizando assim 20 empresas selecionadas para a análise.

\section{Análise dos resultados}

Os resultados da pesquisa estão divididos em dois subtópicos: I) análise da conformidade das empresas dos critérios nas três áreas principais, com a descrição individual de cada área e II) Análise da conformidade das empresas dos critérios nas oito categorias.

\subsection{Análise da conformidade das empresas dos critérios nas três áreas principais}

A análise dos dados referentes às três áreas principais mostra que, na área de Governança, na qual consta a existência do comitê e sua composição nos Formulários de Referência, 50\% das empresas do segmento Novo Mercado e 30\% do segmento Tradicional estão em conformidade com os critérios de "Governaça" constantes no modelo apresentado por Ferrarini, Maloney e Ungureanu (2009). Para a área de "Política de Evidenciação" há certo equilíbrio de evidenciação entre os segmentos. Já na terceira área que trata da "Evidenciação individual dos executivos e não executivos" as empresas do Novo Mercado preencheram $75 \%$ dos critérios contra $45 \%$ das empresas do segmento Tradicional.

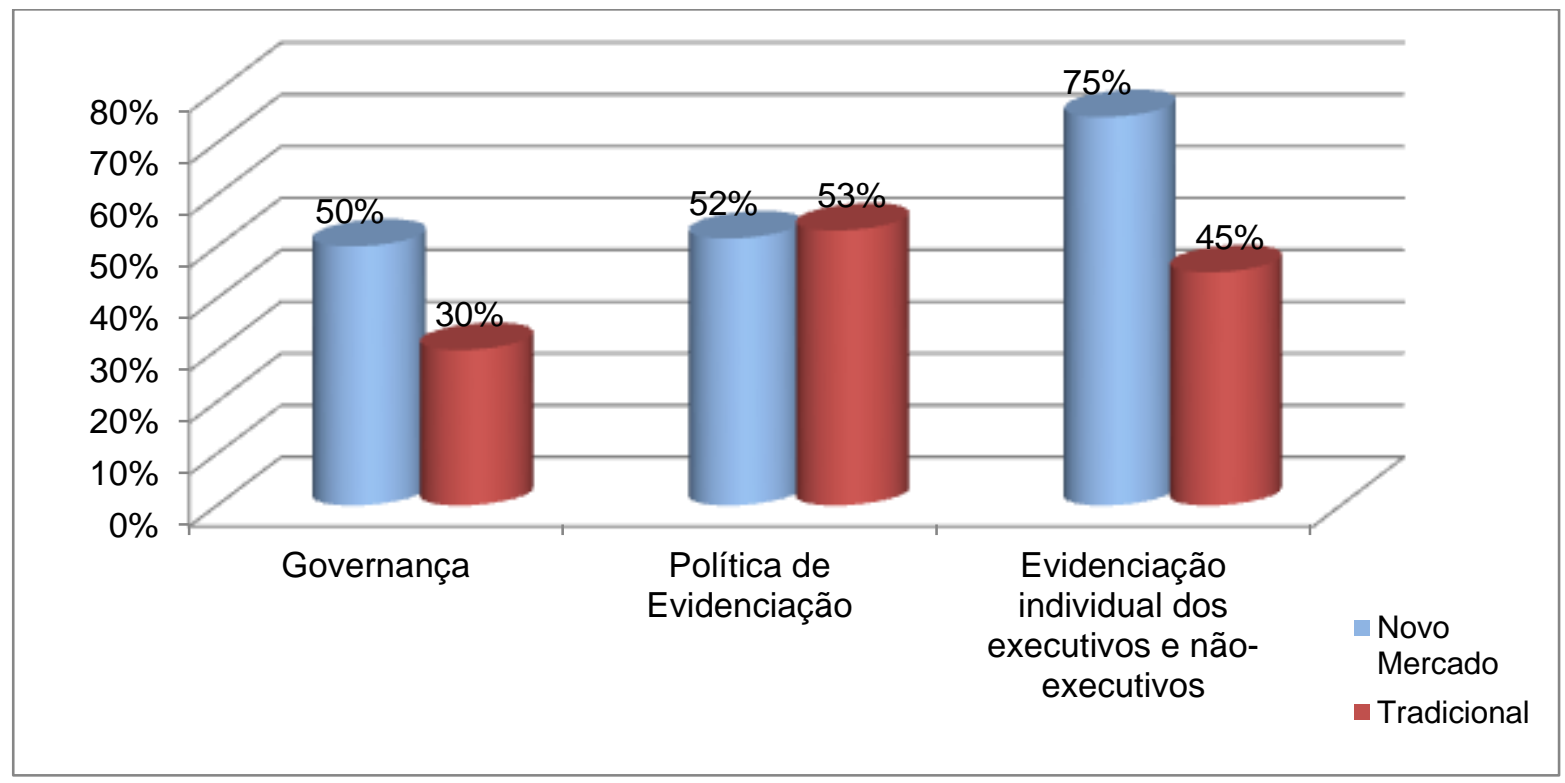

\subsubsection{Análise da área de Governança}

Gráfico 1 - Três principais áreas

A análise da área de Governança possui dois critérios: existência do Comitê de Remuneração e a sua composição. Os resultados por empresa apresentam-se no Quadro 2 segregados por segmento. Observa-se que as empresas que apresentaram maior evidenciação foram Ultrapar, Marfrig, TIM, Energias BR, Petrobras e Telefônica Brasil, que atenderam aos dois critérios estabelecidos na pesquisa. 
REAVI

\begin{tabular}{|c|c|c|c|c|c|}
\hline & Área & \multicolumn{4}{|c|}{ 1. Governança } \\
\hline & \multirow{2}{*}{$\begin{array}{c}\text { Categoria } \\
\text { Empresa }\end{array}$} & \multicolumn{4}{|c|}{ 1. Comitê de Remuneração } \\
\hline & & 1. Existência & 2. Composição & Total de pontos & $\%$ Total da empresa \\
\hline \multirow{11}{*}{$\begin{array}{c}\text { Novo } \\
\text { Mercado }\end{array}$} & JBS & 0 & 0 & 0 & 0,00 \\
\hline & Ultrapar & 1 & 1 & 2 & 100,00 \\
\hline & BRF SA & 1 & 0 & 1 & 50,00 \\
\hline & Marfrig & 1 & 1 & 2 & 100,00 \\
\hline & Cosan & 1 & 0 & 1 & 50,00 \\
\hline & Tim Part S/A & 1 & 1 & 2 & 100,00 \\
\hline & Embraer & 0 & 0 & 0 & 0,00 \\
\hline & Sabesp & 0 & 0 & 0 & 0,00 \\
\hline & Magaz Luiza & 0 & 0 & 0 & 0,00 \\
\hline & Energias BR & 1 & 1 & 2 & 100,00 \\
\hline & Total de pontos & 6 & 4 & 10 & 50,00 \\
\hline \multirow{11}{*}{ Tradicional } & Petrobras & 1 & 1 & 2 & 100,00 \\
\hline & Eletrobras & 0 & 0 & 0 & 0,00 \\
\hline & Telef Brasil & 1 & 1 & 2 & 100,00 \\
\hline & Ambev & 1 & 0 & 1 & 50,00 \\
\hline & \begin{tabular}{|l|} 
Viavarejo \\
\end{tabular} & 0 & 0 & 0 & 0,00 \\
\hline & Embratel Part & 0 & 0 & 0 & 0,00 \\
\hline & \begin{tabular}{|l|} 
Cemig \\
\end{tabular} & 0 & 0 & 0 & 0,00 \\
\hline & Sid Nacional & 0 & 0 & 0 & 0,00 \\
\hline & CPFL Energia & 0 & 0 & 0 & 0,00 \\
\hline & Lojas Americanas & 1 & 0 & 1 & 50,00 \\
\hline & Total de pontos & 4 & 2 & 6 & 30,00 \\
\hline
\end{tabular}

Quadro 2 - Dados da área 1 - Governança por segmento e por empresa
Universidade do Estado de Santa Catarina

Centro de Educação Superior do Alto Vale do Itajaí

A seguir, no Quadro 3, estão expostos os resultados obtidos na análise da Área 1 Governança. As empresas do Novo Mercado apresentaram pequena vantagem na evidenciação destes critérios quando comparadas as empresas do Mercado Tradicional. Conforme consta no Quadro 3, O atendimento desta área foi de 50\% para as empresas do Novo Mercado e 30\% das empresas do Mercado Tradicional.

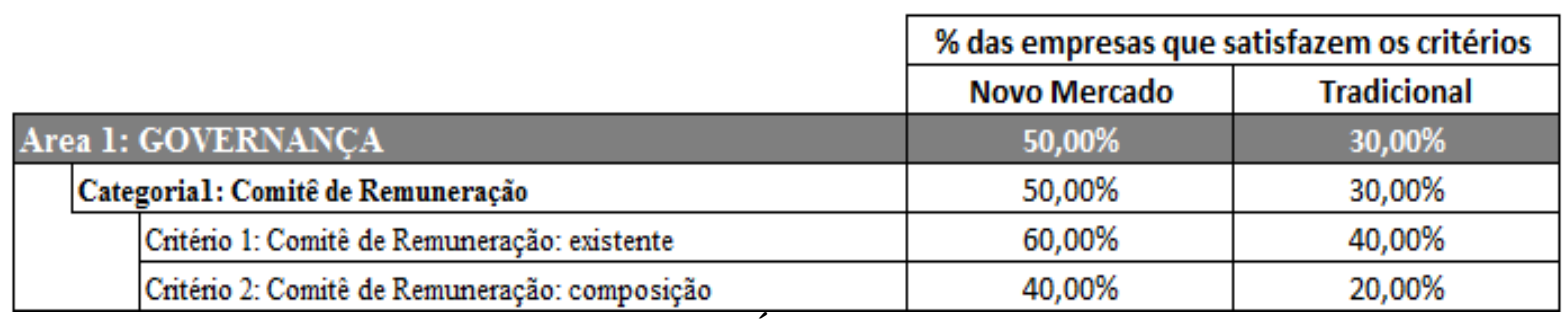

Quadro 3 - Área 1: Governança

Para verificar se existe diferença significativa entre as médias dos dois grupos, aplica-se o teste t de Student com 95\% de confiança, cujos resultados se apresentam no Tabela 3. Através do valor encontrado, pode ser verificado que houve diferença significativa nas amostras definidas, comprovando estatisticamente que as empresas do Novo Mercado tiveram melhor evidenciação do que as empresas do Mercado Tradicional.

\begin{tabular}{l|c|c}
\hline & Novo Mercado & Tradicional \\
\hline Tamanho da Amostra & 10 & 10 \\
\hline
\end{tabular}




\begin{tabular}{l|cc}
\hline Média Aritmética & 50,00 & 30,00 \\
\hline Desvio-padrão & 47,14 & 42,16 \\
\hline Nível de Significância & \multicolumn{2}{|c}{0,05} \\
\hline Teste t de Student & \multicolumn{2}{|c}{0,3306} \\
\hline
\end{tabular}

Tabela 3 - Análise estatística Área 1: Governança

\subsubsection{Análise da área de Política de Remuneração}

Os dados obtidos para a análise da área de Política de Remuneração apresentam-se no Quadro 4, divididos em quatro categorias e treze critérios. Os dados estão dispostos por segmento de governança e em seguida por empresa.

\begin{tabular}{|c|c|c|c|c|c|c|c|c|c|c|c|c|c|c|c|c|}
\hline & \multirow{3}{*}{\begin{tabular}{|c|} 
Área \\
Categuria \\
Impresu/Critérivs \\
\end{tabular}} & \multicolumn{15}{|c|}{ 2.Pulitica de Renuneraçio } \\
\hline & & \multicolumn{3}{|c|}{ 2. Polinica de Remumençái } & \multicolumn{3}{|c|}{ 3. Condiçies des contratos } & \multicolumn{3}{|c|}{ 4. Preparnçàs tunada de decisio } & \multicolumn{4}{|c|}{ 5. Informaçies declaraçio de renuneraçà } & \multirow{2}{*}{ Iotal pontas } & \multirow[b]{2}{*}{96 Total empress } \\
\hline & & 3 & 4 & 5 & 6 & 7 & 8 & 9 & 10 & 11 & 12 & 13 & 14 & 15 & & \\
\hline \multirow{11}{*}{$\begin{array}{l}\text { Segmento - } \\
\text { Novo } \\
\text { Mercado }\end{array}$} & IBS & 1 & 1 & 1 & 0 & 0 & 0 & 0 & 0 & 0 & 1 & 0 & 0 & 1 & 5 & 38,46 \\
\hline & Ultrager & 1 & 1 & 1 & 0 & 0 & 1 & 0 & 0 & 1 & 1 & 0 & 1 & 1 & 8 & 61,54 \\
\hline & BRF SA & 1 & 1 & 1 & 0 & 0 & 0 & 0 & 0 & 0 & 1 & 0 & 1 & 1 & 6 & 46,15 \\
\hline & Marfing & 1 & 1 & 1 & 0 & 0 & 0 & 0 & 0 & 0 & 1 & 1 & 1 & 1 & 7 & 53,55 \\
\hline & $\operatorname{Cos} 2 n$ & 1 & 1 & 1 & 0 & 0 & 0 & 0 & 0 & 1 & 0 & 0 & 1 & 1 & 6 & 46,15 \\
\hline & In Part SA & 1 & 1 & 1 & 0 & 0 & 0 & 0 & 0 & 1 & 1 & 1 & 1 & 1 & 8 & 61,54 \\
\hline & Enbraer & 1 & 1 & 1 & 0 & 0 & 0 & 0 & 0 & 1 & 1 & 0 & 1 & 1 & 7 & 53,85 \\
\hline & Sabesp & 1 & 1 & 1 & 0 & 0 & 0 & 0 & 0 & 0 & 1 & 1 & 0 & 1 & 6 & 46,15 \\
\hline & Magaz Luina & 1 & 1 & 1 & 0 & 0 & 0 & 0 & 0 & 0 & 1 & 1 & 1 & 1 & 7 & 53,85 \\
\hline & Energizs BR. & 1 & 1 & 1 & 0 & 0 & 0 & 0 & 1 & 0 & 1 & 1 & 0 & 1 & 7 & 53,85 \\
\hline & Total de poutos & 10 & 10 & 10 & 0 & 0 & 1 & 0 & 1 & 4 & 9 & 5 & 7 & 10 & 67 & 51,54 \\
\hline \multirow{11}{*}{$\begin{array}{l}\text { Segmento- - } \\
\text { Tradicional }\end{array}$} & Petrobcas & 1 & 1 & 1 & 0 & 0 & 0 & 0 & 0 & 1 & 1 & 1 & 0 & 1 & 7 & 53,85 \\
\hline & Eletrobras & 1 & 1 & 1 & 0 & 0 & 0 & 0 & 0 & 0 & 0 & 0 & 0 & 1 & 4 & 30,77 \\
\hline & Telef Brasi & 1 & 1 & 1 & 0 & 0 & 1 & 0 & 0 & 1 & 1 & 0 & 0 & 1 & 7 & 53,85 \\
\hline & Anbev & 1 & 1 & 1 & 0 & 0 & 0 & 0 & 0 & 1 & 1 & 0 & 1 & 1 & 7 & 53,85 \\
\hline & Tianarejo & 1 & 1 & 1 & 0 & 0 & 0 & 0 & 1 & 0 & 1 & 0 & 0 & 1 & 6 & 46,15 \\
\hline & Enbratel Part & 1 & 1 & 1 & 0 & 0 & 0 & 0 & 1 & 1 & 1 & 1 & 0 & 1 & 8 & 61,54 \\
\hline & Cenig & 1 & 1 & 1 & 0 & 0 & 1 & 0 & 0 & 1 & 1 & 0 & 0 & 1 & 7 & 53,85 \\
\hline & SidNacional & 1 & 1 & 1 & 0 & 0 & 0 & 0 & 0 & 0 & 0 & 1 & 0 & 1 & 5 & 38,46 \\
\hline & CPFL Energia & 1 & 1 & 1 & 0 & 0 & 1 & 0 & 1 & 1 & 1 & 1 & 1 & 1 & 10 & 76,92 \\
\hline & Lojas Ameicanas & 1 & 1 & 1 & 0 & 0 & 0 & 0 & 1 & 0 & 1 & 1 & 1 & 1 & 8 & 61,54 \\
\hline & Total de puntos & 10 & 10 & 10 & 0 & 0 & 3 & 0 & 4 & 6 & 8 & 5 & 3 & 10 & 69 & 53,08 \\
\hline
\end{tabular}

Quadro 4 - Dados da Área 2 - Política de Remuneração

A análise da Área 2 - Política de Remuneração apresentou resultados similares quanto à média de evidenciação das duas amostras. As empresas que apresentaram maior atendimento aos critérios estabelecidos foram: CPFL Energia, Embratel e Lojas Americanas no Segmento Tradicional e Ultrapar e Cosan no Segmento Novo Mercado.

As categorias tiveram resultados bastante divergentes, enquanto as categorias Declaração de Política de Remuneração e Informações da Política tiveramresultados que demonstram alta evidenciação, com atendimento de $100 \%$ da Declaração de Política de Remuneração pelos dois segmentos. A Categoria 3: Termos do Contrato apresentou resultados com baixa evidenciação, apenas 3,33\% das empresas do Novo Mercado cumpriram as exigências do Modelo e 10\% das empresas do Mercado Tradicional. 


\begin{tabular}{|c|c|c|}
\hline & \multicolumn{2}{|c|}{$\%$ das empresas que satisfazem os critérios } \\
\hline & Novo Mercado & Tradicional \\
\hline Area 2: POLÍTICA DE REMUNERAĊ̃O & $49,38 \%$ & $52,08 \%$ \\
\hline Categoria 2: Declaração de Política de Remuneração & $100,00 \%$ & $100,00 \%$ \\
\hline Critério 3: Declaração: existente & $100,00 \%$ & $100,00 \%$ \\
\hline Critério 4: Visão geral da politica & $100,00 \%$ & $100,00 \%$ \\
\hline Critério 5: perspectivas: foco no futuro & $100,00 \%$ & $100,00 \%$ \\
\hline Categoria 3: Termos do Contrato & $3,33 \%$ & $10,00 \%$ \\
\hline Critério 6: Duração do contrato & $0,00 \%$ & $0,00 \%$ \\
\hline Critério 7: Periodo do aviso prévio & $0,00 \%$ & $0,00 \%$ \\
\hline Critério 8: Indenizações & $10,00 \%$ & $30,00 \%$ \\
\hline Categoria 4: Preparação e processo de tomada de decisão & $16,67 \%$ & $33,33 \%$ \\
\hline Critério 9: Mandato e composição & $0,00 \%$ & $0,00 \%$ \\
\hline Critério 10: Consultores externos & $10,00 \%$ & $40,00 \%$ \\
\hline Critério 11: Papel da Assembléia Geral & $40,00 \%$ & $60,00 \%$ \\
\hline Categoria 5: Informações da Política & $77,50 \%$ & $65,00 \%$ \\
\hline Critério 12 : Importância relativa fixo/variável & $90,00 \%$ & $80,00 \%$ \\
\hline Critério 13: Principais parâmetros para o bônus anual & $50,00 \%$ & $50,00 \%$ \\
\hline Critério 14: Critérios de desempenho para remuneração baseada em ações & $70,00 \%$ & $30,00 \%$ \\
\hline Critério 15 : Informações suficientes para relacionar remuneração $\mathrm{X}$ desempenho & $100,00 \%$ & $100,00 \%$ \\
\hline
\end{tabular}

Quadro 5 - Área 2: Política de Remuneração

\subsubsection{Análise da área de Evidenciação Individual dos Executivos e Não-Executivos}

Os dados resultantes da coleta de dados nos Formulários de Referência das empresas pesquisadas para a Área 3 que diz respeito à evidenciação individual da remuneação dos executivos e dos não executivos, encontram-se na Quadro 6. As empresas que apresentaram melhores resultados nesta área foram JBS e Marfrig, únicas que atenderam totalmente as exigências do Modelo.

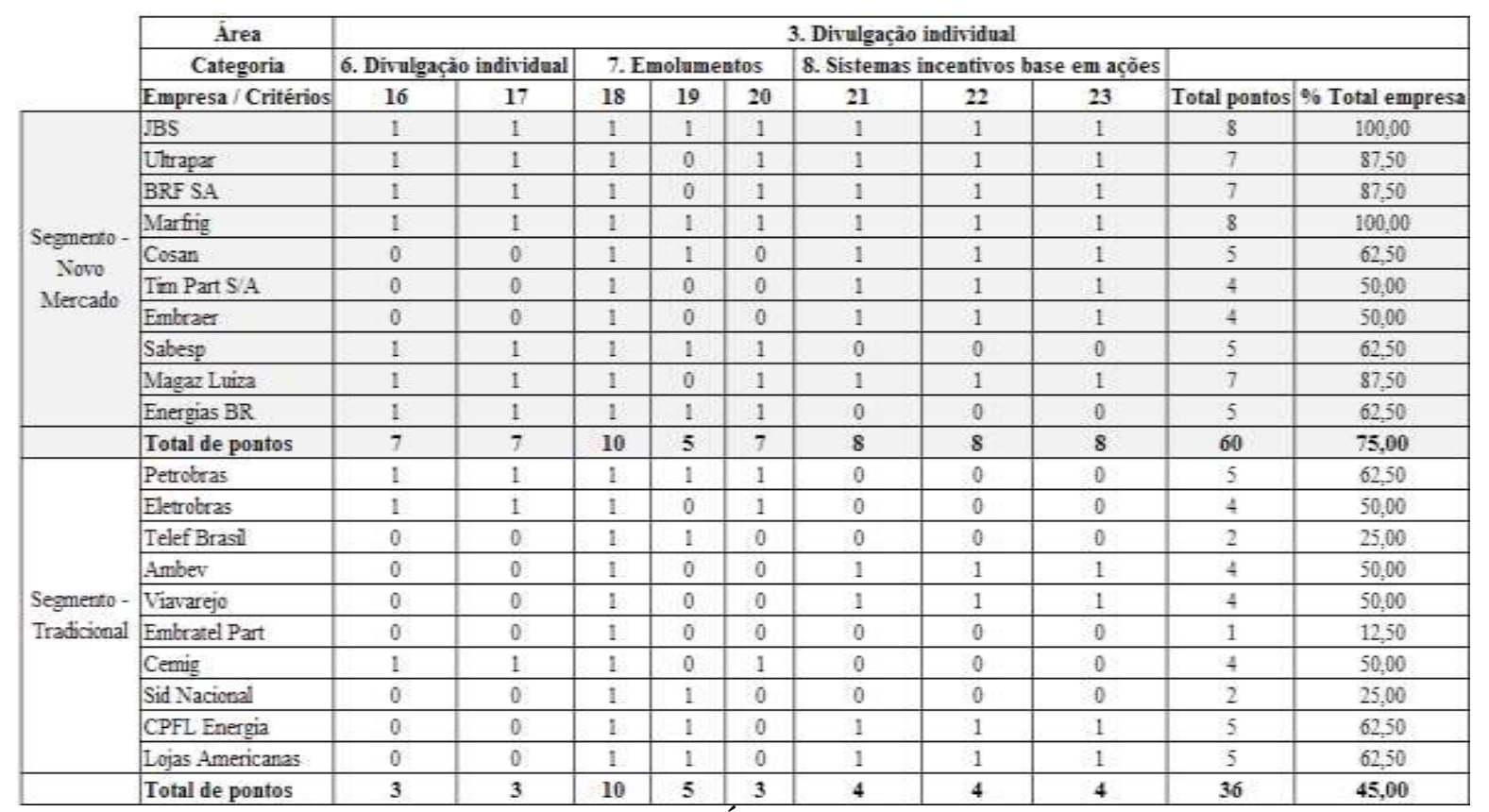

Quadro 6 - Dados da Área 3 - Divulgação individual

No comparativo de resultados dos segmentos, conforme demonstrado no Quadro 7, a amostra de empresas do Novo Mercado apresentou melhor evidenciação do que a amostra de empresas do Mercado Tradicional, com índices de $74,44 \%$ e 43,33\%, respectivamente. Cabe ressaltar que 
quanto ao atendimento dos Critérios 16, 17 e 20, que tratam da remuneração individualdos executivos e não-executivos, algumas empresas possuem Liminar Judicial para não apresentarem tais valores, no caso: Cosan, TIM, Embraer, Telefônica Brasil, Viavarejo, Embratel, Siderurgica Nacional, CPFL Energia e Lojas Americanas.

\begin{tabular}{|c|c|c|}
\hline & \multicolumn{2}{|c|}{$\%$ das empresas que satisfazem os critérios } \\
\hline & Novo Mercado & Tradicional \\
\hline Area 3: EVIDENCIAÇÃO INDIVIDUAL DOS EXECUTIVOS E NÃO-EX & $74,44 \%$ & $43,33 \%$ \\
\hline Categoria 6: Evidenciação individual & $70,00 \%$ & $30,00 \%$ \\
\hline Critério 16: Evidenciação individual dos executivos & $70,00 \%$ & $30,00 \%$ \\
\hline Critério 17: Evidenviação individual dos não-executivos & $70,00 \%$ & $30,00 \%$ \\
\hline Categoria 7: Emolumentos & $73,33 \%$ & $60,00 \%$ \\
\hline Critério 18: Salário Individual / taxas & $100,00 \%$ & $100,00 \%$ \\
\hline Critério 19: Bônus individual e outros beneficios & $50,00 \%$ & $50,00 \%$ \\
\hline Critério 20: Informações do ano anterior & $70,00 \%$ & $30,00 \%$ \\
\hline Categoria 8: Sistemas de incentivo baseado em ações & $80,00 \%$ & $40,00 \%$ \\
\hline Critério 21: Ações /opções concedidas & $80,00 \%$ & $40,00 \%$ \\
\hline Critério 22: Ações / opções exercidas & $80,00 \%$ & $40,00 \%$ \\
\hline Critério 23: Ações / opções não exercidas & $80,00 \%$ & $40,00 \%$ \\
\hline
\end{tabular}

Quadro 7 - Área 3: Evidenciação individual dos executivos e não executivos

Para evidenciar se há diferença significativa entre as médias em cada uma das amostras, aplica-se um teste $t$ com 95\% de confiança, cujos resultados apresentam-se na Tabela 4. Através do valor encontrado, pode-se verificar que houve diferença significativa nas amostras definidas, comprovando estatisticamente que as empresas do Novo Mercado apresentam melhor evidenciação individual dos executivos e não executivos que as empresas do Mercado Tradicional.

\begin{tabular}{l|c|c}
\hline & Novo Mercado & Tradicional \\
\hline Tamanho da Amostra & 10 & 10 \\
\hline Média Aritmética & 75,00 & 45,00 \\
\hline Desvio-padrão & 19,54 & 17,87 \\
\hline Nível de Significância & \multicolumn{2}{|c}{0,05} \\
\hline Teste t de Student & \multicolumn{2}{|c}{0,0021} \\
\hline
\end{tabular}

Tabela 4 - Análise estatística Área 3: Evidenciação individual dos executivos e não executivos

\subsection{Análise da conformidade das empresas dos critérios nas oito categorias}

As categorias que se apresentaram com maior conformidade de critérios nas oito categorias segundo o modelo de avaliação da evidenciação proposto por Ferrarini, Maloney e Ungureanu (2009), demonstram que as empresas do Novo Mercado possuem maior evidenciação nas categorias "Comitê de Remuneração" com percentual de 50\%, "Informações da Política" (77,50\%), "Evidenciação Individual" (70\%), "Emolumentos" (73.33\%) e na categoria "Sistemas de incentivo baseado em ações" (80\%).

Na categoria "Declaração de Política de Remuneração", ambos os segmentos apresentaram $100 \%$ de conformidade.

Há um menor alinhamento com o modelo para ambos os segmentos para as categorias: "Termos do Contrato" para os critérios de duração dos contratos dos executivos, o período do aviso prévio e informações de indenizações em caso de cessação do contato; e "Preparação do 
Processo de tomada de decisão", composta pelos critérios de mandato e composição da comissão de remuneração, a divulgação dos nomes dos consultores externos cujos serviços foram utilizados na determinação da política de remuneração e por fim, o papel da Assembleia Geral no processo de fixação da remuneração.

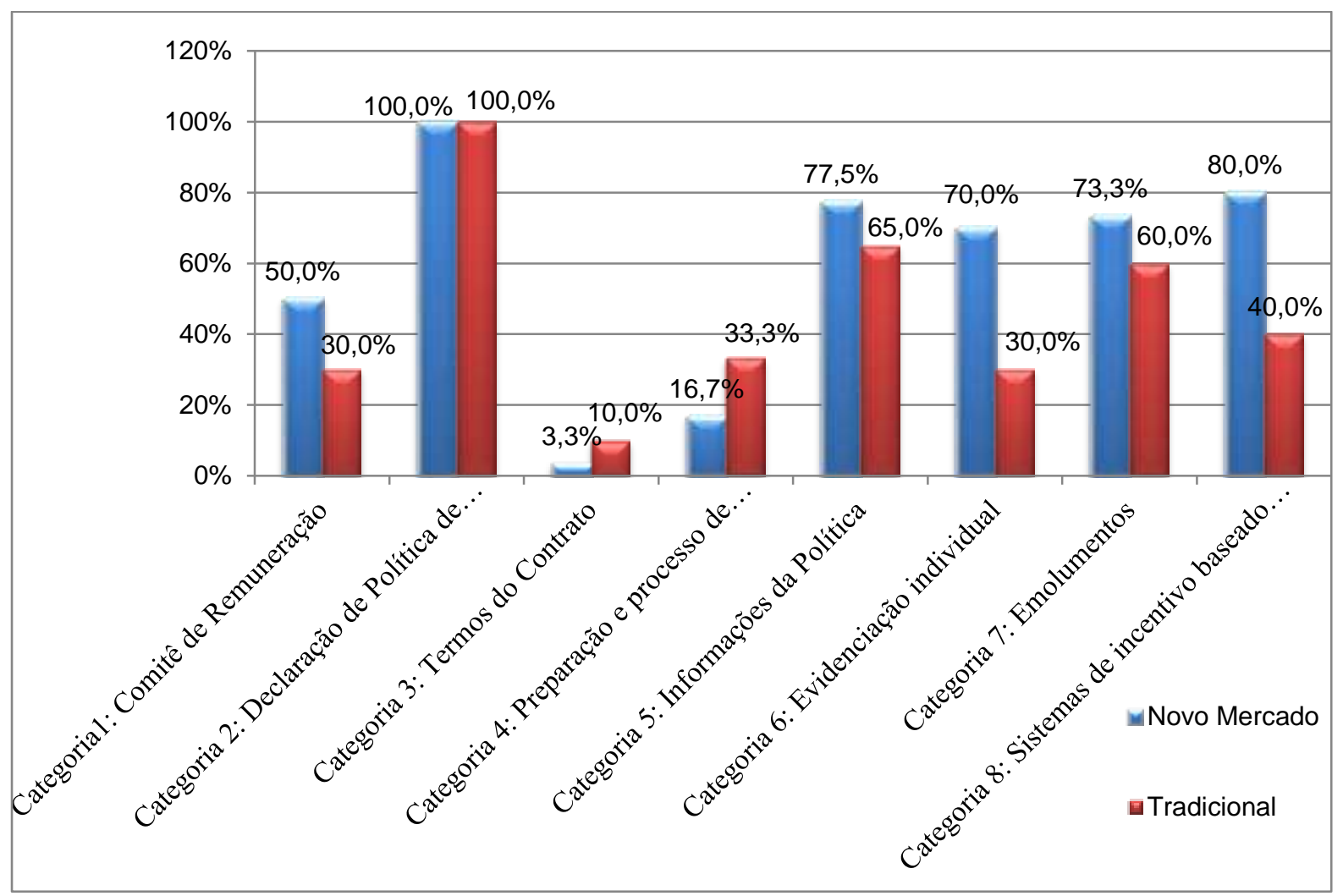

Gráfico 2 - Análise das oito categorias do Modelo

O resumo dos resultados está apresentado de forma consolidada no Quadro 8 em percetual de empresas que satisfazem cada critério, categoria e área. O Modelo é dividido em três áreas: 1. Governança, 2. Política de Remuneração e 3. Evidenciação Individual de Executivos e Não Executivos e das oito categorias. 


\begin{tabular}{|c|c|c|c|}
\hline & \multicolumn{2}{|c|}{ \% das empresas que satisfazem os critérios } \\
\hline & & Novo Mercado & Tradicional \\
\hline \multicolumn{2}{|c|}{ Area 1: GOVERNANÇA } & $\mathbf{5 0 , 0 0 \%}$ & $30,00 \%$ \\
\hline \multicolumn{2}{|c|}{ Categoria1: Comitê de Remuneração } & $50 \%$ & $30 \%$ \\
\hline & Critério 1: Comitê de Remuneração: existente & $30 \%$ & $20 \%$ \\
\hline & Critério 2: Comitê de Remuneração: composição & $20 \%$ & $10 \%$ \\
\hline \multicolumn{2}{|c|}{ Area 2: POLÍIICA DE REMUNERAÇÃO } & $49,38 \%$ & $52,08 \%$ \\
\hline \multicolumn{2}{|c|}{ Categoria 2: Declaração de Política de Remuneração } & $100 \%$ & $100 \%$ \\
\hline & Critério 3: Declaração: existente & $100 \%$ & $100 \%$ \\
\hline & Critério 4: Visão geral da política & $100 \%$ & $100 \%$ \\
\hline & Critério 5: perspectivas: foco no futuro & $100 \%$ & $100 \%$ \\
\hline \multicolumn{2}{|c|}{ Categoria 3: Termos do Contrato } & $3,33 \%$ & $10,00 \%$ \\
\hline & Critério 6: Duração do contrato & $0,00 \%$ & $0,00 \%$ \\
\hline & Critério 7: Período do aviso prévio & $0,00 \%$ & $0,00 \%$ \\
\hline & Critério 8: Indenizações & $10,00 \%$ & $30,00 \%$ \\
\hline \multicolumn{2}{|r|}{ Categoria 4: Preparação e processo de tomada de decisão } & $16,67 \%$ & $33,33 \%$ \\
\hline & Critério 9: Mandato e composição & $0,00 \%$ & $0,00 \%$ \\
\hline & Critério 10: Consultores externos & $10,00 \%$ & $40,00 \%$ \\
\hline & Critério 11: Papel da Assembléia Geral & $40,00 \%$ & $60,00 \%$ \\
\hline \multicolumn{2}{|c|}{ Categoria 5: Informações da Política } & $77,50 \%$ & $65,00 \%$ \\
\hline & Critério 12: Importância relativa fixo/variável & $90,00 \%$ & $80,00 \%$ \\
\hline & Critério 13: Principais parâmetros para o bônus anual & $50,00 \%$ & $50,00 \%$ \\
\hline & Critério 14: Critérios de desempenho para remuneração baseada em ações & $70,00 \%$ & $30,00 \%$ \\
\hline & Critério 15: Informações suficientes para relacionar remuneração $\mathrm{X}$ desempenho & $100,00 \%$ & $100,00 \%$ \\
\hline \multicolumn{2}{|r|}{ Area 3: EVIDENCIAÇÃO INDIVIDUAL DOS EXXCUIIVOS ENÃO-EXXCUIIVOS } & $74,44 \%$ & $\mathbf{4 3 , 3 3 \%}$ \\
\hline \multicolumn{2}{|c|}{ Categoria 6: Evidenciação indi vidual } & $70,00 \%$ & $30,00 \%$ \\
\hline & Critério 16: Evidenciação individual dos executivos & $70,00 \%$ & $30,00 \%$ \\
\hline & Critério 17: Evidenviação individual dos não-executivos & $70,00 \%$ & $30,00 \%$ \\
\hline \multicolumn{2}{|r|}{ Categoria 7: Emolumentos } & $73,33 \%$ & $60,00 \%$ \\
\hline & Critério 18: Salário Individual / taxas & $100,00 \%$ & $100,00 \%$ \\
\hline & Critério 19: Bônus individual e outros benefícios & $50,00 \%$ & $50,00 \%$ \\
\hline & Critério 20: Informações do ano anterior & $70,00 \%$ & $30,00 \%$ \\
\hline \multicolumn{2}{|r|}{ Categoria 8: Sistemas de incentivo baseado em ações } & $80,00 \%$ & $40,00 \%$ \\
\hline & Critério 21: Ações /opções concedidas & $80,00 \%$ & $40,00 \%$ \\
\hline & Critério 22: Ações / opções exercidas & $80,00 \%$ & $40,00 \%$ \\
\hline & Critério 23: Ações / opções não exercidas & $80,00 \%$ & $40,00 \%$ \\
\hline
\end{tabular}

Quadro 8 - Resumo dos resultados

\section{Considerações Finais}

Esta pesquisa teve por objetivo verificar a evidenciação da remuneração dos administradores nas empresas brasileiras listadas na BM\&FBOVESPA com maior e menor grau de governança corporativa, com base no do modelo europeu de avaliação proposto por Ferrarini, Maloney e Ungureanu (2009).

A amostra utilizada na pesquisa foram 20 empresas listadas na BM\&FBOVESPA, com o maior valor de Receita Operacional Líquida, divididas em dois segmentos extremos de governança, ou seja, Tradicional e Novo Mercado. A seleção da amostra das empresas do Novo Mercado representam 55,68\% do total de toda a Receita Operacional Líquida das empresas que compõe este nível de governança e as 10 empresas do selecionadas do nível de governança denominado Tradicional, representam $77 \%$ da ROL das empresas do seu segmento.

O estudo demonstrou que para algumas áreas há maior evidenciação pelo segmento Novo Mercado que pelo Tradicional, como Governança (50\% versus $30 \%$ ) e Evidenciação Individual ( $75 \%$ versus $45 \%$ ) respectivamente. A categoria mais evidenciada foi a Declaração de Política de Remuneração, publicada por $100 \%$ das empresas. A categoria menos evidenciada foi a que 


\section{REAVI}

Universidade do Estado de Santa Catarina

Centro de Educação Superior do Alto Vale do Itajaí

contém os Termos do Contrato com os executivos diretores (3,33\% empresas do Novo Mercado e 10\% pelo segmento Tradicional). Das 20 empresas analisadas, aquelas que apresentaram maior evidenciação foram a Marfrig, seguidas da Ultrapar. Em terceiro lugar, estão com a mesma pontuação a Energias BR e Petrobras. Conclui-se que o alinhamento das informações prestadas pelas empresas utilizando-se o modelo de avaliação de evidenciação de Ferrarini, Maloney e Ungureanu é, de maneira geral, maior nas empresas com maior nível de governança, ou seja, optantes pelo segmento do Novo Mercado.

A maior limitação da pesquisa foi o tamanho da amostra, que compromete a generalização dos resultados. As sugestões para trabalhos futuros são para que sejam utilizadas outras técnicas estatísticas, que a amostra da pesquisa seja ampliada e verificada a evidenciação de outros itens do Formulário de Referência.

\section{Referências}

BEUREN, I. M.; SILVA, J.O. Remuneração dos executivos nas maiores empresas brasileiras da Bovespa: análise da evidenciação à luz do modelo de Ferrarini, Moloney e Ungureanu. RIGC. Volume X, nº 19, enero/junio 2012.

CARVALHO, Antonio Gledson de. Governança Corporativa no Brasil em Perspectiva. In: Revista de Administração. São Paulo. v. 37, n. 3, p. 19-32, julho/setembro de 2002.

COMISSÃO DE VALORES MOBILIÁRIOS. Anexo n ${ }^{\circ} \mathbf{2 4}$ da Instrução CVM no 480, de 7 de dezembro de 2009. Disponível em: 〈http://www.cvm.gov.br/>. Acesso em: 09 nov. 2013.

GODOY, Paulo de; MARCON, Rosilene. Teoria da agência e os conflitos organizacionais: a influência das transferências e das promoções nos custos de agência em uma instituição bancária. Revista de Administração Mackenzie, v. 7, n. 4, 2008

FERRARINI, G.; MOLONEY, N.; UNGUREANU, M.C. (2009): Understanding directors' pay in Europe: a comparative and empirical analysis. June, 2009. ECGI - Law WorkingPaper, n. 126/2009. Disponível em: 〈http://papers.ssrn.com/sol3/papers.cfm?abstract_id=1418463〉. Acesso em: 09 nov. 2013.

GIL, Antonio Carlos. Métodos e técnicas de pesquisa social. 3. ed. São Paulo: Atlas, 1991.

GIL, Antonio Carlos. Como elaborar projetos de pesquisa. 4.ed. São Paulo: Atlas, 2008.

HENDRIKSEN, É. S.; VAN BREDA, M. F. Teoria da contabilidade. 5. ed. Tradução de Antonio Zoratto Sanvicente. São Paulo: Atlas, 2007.

INSTITUTO BRASILEIRO DE GOVERNANÇA CORPORATIVA. Código das melhores práticas de governança corporativa. 4..ed. 2009. Disponível em: 〈http://www.ibgc.org.br./>. Acesso em: 10 nov. 2013.

JENSEN, M. C.; MECKLING, W. H. Theory of the firm: Managerial behavior, agency costs and ownership structure. Journal of financial economics, v. 3, n. 4, p. 305-360, 1976.

RICHARDSON, R. J. Pesquisa social: métodos e técnicas. 2. ed. São Paulo: Atlas, 1989. 
SILVA, Júlio Orestes da; BEUREN, Ilse Maria. Evidenciação da Remuneração Variável dos Executivos nas Maiores Empresas Brasileiras Listadas na Bovespa. In: IV Congresso ANPCONT. Disponível em: www.furb.br/congressocont/2010/trabalhos/cue_238.pdf

VENTURA, Ana Flávia Albuquerque. Remuneração executiva, governança corporativa e desempenho: uma análise nas empresas listadas na BM\&FBOVESPA. Dissertação (Mestrado). UnB-UFPB-UFRN, 2013.

VIEIRA, Solange Paiva; MENDES, André Gustavo Salcedo Teixeira. Governança corporativa: uma análise de sua evolução e impactos no mercado de capitais brasileiro. Revista

Organizações em Contexto-online, v. 2, n. 3, p. 48-67, 2005.

YAMAMOTO, M. M., PRADO, J.E de A. A Governança e o valor das empresas: o respeito dos acionistas é um dever moral das companhias que captam recursos do público. São Paulo: Revista BOVESPA, N.88, P.42-43, Out-dez, 2003. 